\title{
In vitro antioxidant and antiurolithiatic activity of Commicarpus chinensis (L.) Heimert in ethylene glycol induced urolithiasis in rats
}

\author{
Simmi Singh, Ambika Sharma*, A.J. Asnani and Ashish Kumar*** \\ J.L. Chaturvedi College of Pharmacy, Nagpur, Maharashtra-440009, India \\ * Department of Veterinary Biochemistry, College of Veterinary Science and Animal Husbandry, DUVASU, Mathura-281001, Uttar Pradesh, \\ India \\ **All India Institute of Medical Sciences (AIIMS), Rishikesh, Uttarakhand-249 203, India
}

\begin{tabular}{l} 
Article Info \\
\hline Article history \\
Received 10 July 2021 \\
Revised 28 August 2021 \\
Accepted 29 August 2021 \\
Published Online 30 December 2021
\end{tabular}

Keywords

Commicarpus chinensis (L.) Heimert DPPH

FRAC

Ethylene glycol

Hyperoxaluria

Urolithiasis

\begin{abstract}
Commicarpus chinensis (L.) Heimert is traditionally used in folk medicine and siddha. Different parts of this plant are used for the treatment of various ailments in the indigenous system of medicine. The purpose of this study was to evaluate the free radical scavenging activity and antiurolith potential of root extracts of $C$. chinensis. The study was done by using various in vitro methods such as DPPH, FRAC and nitric oxide scavenging assays. Urolithiasis was induced by administering $0.75 \%$ ethylene glycol orally for 28 days in male Wistar rats. The preventive as well as curative doses of $250 \mathrm{mg} / \mathrm{kg}$ were administered from day 1 to day 28 and day 15 to day 28 day, respectively. On the $28^{\text {th }}$ day, $24 \mathrm{~h}$ urine, and serum was collected and various biochemical parameters were estimated. The results showed that C. chinensis root extracts possessed antioxidant properties including free radical scavenging, ferric reducing antioxidant capacity and nitrite scavenging activities. The results also showed a decrease in urinary volume and urinary $\mathrm{pH}$ in nephrolithiasic rats. Administration of $C$. chinensis root extracts has significantly increased the urine volume and the level of calculi inhibitor like magnesium and decreased the level of calcium, oxalate, phosphate and uric acid in urine. Test extract supplement also increased the glomerulus activity of the kidney by restoring the levels of creatinine and uric acid in serum. The results of present comprehensive analysis demonstrated that $C$. chinensis root possess potential antioxidant activity and could be used as a viable source of natural antioxidant and an effective free radical scavenger. It also indicates root extracts of $C$. chinensis have significant activity in urolithiasis.
\end{abstract}

\section{Introduction}

Free radicals or reactive oxygen species are linked with many pathophysiological conditions, such as cardiovascular diseases, carcinogenesis, ageing, diabetes and neurodegenerative diseases. A free radical is any molecular species capable of independent existence that contains an unpaired electron in an atomic orbital and these radicals are unstable and highly reactive. They have an ability to damage biologically important molecules such as carbohydrates, proteins, lipids, and DNA (Young and Woodside, 2001). They are either produced during the metabolic processes in the body or from exposure to some sources such as X-rays, smoking, pollutants, industrial chemicals and leading to oxidative stress, arising as a result of an imbalance between free radical production and antioxidant defences (Lobo et al., 2010).

An antioxidant is a molecule that prevent damages caused by the free radicals by donating an electron so as to neutralize it. Natural substances present in medicinal plants are being explored as

Corresponding author: Dr. Ashish Kumar

All India Institute of Medical Sciences (AIIMS), Rishikesh, Uttarakhand-249 203, India

E-mail: ashishvet77@gmail.com

Tel.: +91-7838876105

Copyright (c) 2021 Ukaaz Publications. All rights reserved.

Email: ukaaz@yahoo.com; Website: www.ukaazpublications.com therapeutic antioxidants. Many antioxidant compounds, particularly the flavonoids, and phenolic compounds naturally occurring in plant sources have been identified as free radical scavengers (Goncalves et al., 2017; Huyut et al., 2017).

Nephrolithiasis is one of the most common urological conditions. Urolithiasis indicates the presence of stones and calcification within the urinary tract. The formation of renal stones is a consequence of increased urinary supersaturation with subsequent formation of crystalline particles that includes crystal nucleation, crystal growth, crystal aggregation, and crystal retention (Aggarwal et al., 2013). Diet particularly dietary calcium and fluid intake influence the threat of nephrolithiasis and it is now thought of not only as a disease of morbidity, but as a marker of potentially lethal conditions, such as diabetes and cardiovascular disease (Ziemba and Matlaga, 2017). Kidney stone disease is associated, directly or indirectly, with food consumption (Guha et al., 2019). In India, nearly $12 \%$ of total population reported to be prone to urinary stones (Sofia, 2016). About $80 \%$ of calculi are composed primarily of calcium oxalate $(\mathrm{CaOx})$ and/or calcium phosphate (Bhat et al., 2018).

Different treatments, namely; extracorporeal shock wave lithotripsy (SWL), medications, percutaneous nephrolithotomy are used. However, these treatments are associated with the recurrence (Kirkali et al., 2015), SWL associated vascular trauma to the kidney and surrounding organs (McAteer and Evan, 2008). The cost to 
care for stone disease is increasing day-by-day, forcing us to look for some efficient and economical alternatives. Therefore, it is worthy to look for safer and effective alternatives by means of phytotherapy or herbal medicine. Herbal medicines are very commonly used in India since ages for the cure of various ailments. Now, Western world and Americans are also adopting these natural ways of treatment through phytotherapy or herbs. May plants and their extracts, namely; Hibiscus sabdariffa (Laikangbam and Damayanti Devi, 2012), Citrus aurantium (Li et al., 2015), Oldoapur purascens (Mosquera et al., 2020) demonstrated the promising role in the prevention and management of kidney stones.

C. chinensis is commonly known as diffuse hogweed belonging to the family Nyctaginaceae (Bougainvillea family) and distributed in southern China, Pakistan, India, Myanmar, Thailand, Vietnam, Malaysia, Indonesia. It is commonly used in folk medicine and siddha. Different parts of this plant are being used for the treatment of various diseases in the indigenous system of medicine. The leaves are used for treating scabies and itching. It possesses anti-ulcer (Madhurkar and Sayeed U1 Hasan, 2014), analgesic and anti inflammatory (Madhurkar et al., 2014), antispasmodic activities (Halkai et al., 2012). In addition, preliminary phytochemical screening has indicated the presence of steroids, tannins, flavonoids, saponins, carbohydrates and proteins in the leaves of $C$. chinensis (Boxi et al., 2010). However, so far no scientific study has been reported regarding the antioxidant, and antiurolithiatic property of the root extract of C. chinensis. In the present work, we evaluated the antioxidant activity and possible prophylactic as well as therapeutic potential of $C$. chinensis root extracts in experimentally induced nephrolithiasis in rats.

\section{Materials and Methods}

\subsection{Collection of plant material and authentication}

The fresh roots of $C$. chinensis (Nyctaginaceae) were collected from Firozabad, Uttar Pradesh, India and authenticated from Department of Botany, R.T.M. Nagpur University, Nagpur, Maharashtra, India. The authentication No. is 9315.2.2.

\subsection{Extraction}

The Soxhlet extractor was used for the extraction. The powder of C. chinensis roots was extracted with ethanol. The extracts were obtained from continuous hot percolation or Soxhlet extraction or soxhlation. After extraction, the solvent was removed by means of a rotary evaporator, yielding the extracted compound. The water extracts were obtained from maceration process. In this process, the moistened drug is left in contact with menstrum for $24 \mathrm{~h}$. During this period, the menstrum dissolves the active constituents of the drug and becomes almost saturated with it and thereafter dried in oven at $60^{\circ} \mathrm{C}$.

\subsection{Phytochemical analysis}

Both the extracts were screened for various phytoconstituents (alkaloids, saponins, tannins, flavonoids, anthraquinones, sterol, glycosides, simple sugars) using standard procedures (Purohit et al., 2020).

\subsection{Antioxidant activity (In vitro)}

The evaluation of antioxidant activity of extracts of $C$. chinensis was done through various in vitro assays.

\subsubsection{DPPH radical scavenging assay}

The free radical scavenging activity of different extracts of C. chinensis and L-ascorbic acid (vitamin C) was measured in terms of hydrogen donating or radical-scavenging ability using the stable radical DPPH as per the methods described by Blois (1958). About $0.1 \mathrm{mM}$ solution of DPPH (1,1-dipheny-2 picrylhydrazyl) in ethanol was prepared and $1 \mathrm{ml}$ of this solution was added to $3 \mathrm{ml}$ of extract solution in water at different concentrations $(20-100 \mu \mathrm{g} /$ $\mathrm{ml})$. The reaction mixture was mixed properly and kept in the dark at room temperature for $30 \mathrm{~min}$. The absorbance was measured at $517 \mathrm{~nm}$ spectrophotometrically. Vitamin C was used as a standard. Lower absorbance of the reaction mixture indicates higher free radical scavenging activity. The experiment was done in triplicate at each concentration.The capability to scavenge the DPPH radical was calculated using the following equation:

DPPH scavenged $(\%)=\left(\left(\mathrm{A}_{\mathrm{C}}-\mathrm{A}_{\mathrm{T}}\right) \times 100\right) /\left(\mathrm{A}_{\mathrm{C}}\right)$

where,

$\mathrm{A}_{\mathrm{C}}$ is the absorbance of the control.

$\mathrm{A}_{\mathrm{T}}$ is the absorbance of the extracts/standard.

Then $\%$ of inhibition was plotted against concentration, and from the graph $\mathrm{IC}_{50}$ was calculated.

\subsubsection{Determination of reducing power (Ferrous reducing antioxidant capacity-FRAC assay)}

The ferrous reducing antioxidant capacity (FRAC) of extracts was evaluated by the method of Oyaizu (1986).Various concentrations of the extracts $(20-100 \mu \mathrm{g} / \mathrm{ml})$ in $1 \mathrm{ml}$ of deionized water were mixed with phosphate buffer $(2.5 \mathrm{ml}, 0.2 \mathrm{M}, \mathrm{pH} 6.6)$ and $1 \%$ potassium ferricyanide $(2.5 \mathrm{ml})$. The mixture was incubated at $50^{\circ} \mathrm{C}$ for 20 min. Aliquots of trichloroacetic acid $(2.5 \mathrm{ml}, 10 \%)$ were added to the mixture, and centrifuged at $3000 \mathrm{rpm}$ for $10 \mathrm{~min}$. Following centrifugation, $2.5 \mathrm{ml}$ of supernatant was separated, mixed with $2.5 \mathrm{ml}$ of distilled water and $0.5 \mathrm{ml}$ of $0.1 \%$ freshly prepared ferric chloride $\left(\mathrm{FeCl}_{3}\right)$ solution. The absorbance was measured at $700 \mathrm{~nm}$. The experiment was done in triplicate at each concentration.

\subsubsection{Nitric oxide scavenging activity}

Nitric oxide generated from sodium nitroprusside was measured by the Greiss reaction as per the method of Marcocci et al. (1994). Sodium nitroprusside $(5 \mathrm{mM})$ in $0.5 \mathrm{M}$ phosphate buffer, $\mathrm{pH} 7.4$, spontaneously generates nitric oxide in aqueous solution. Nitric oxide interacts with oxygen to produce stable products, leading to the production of nitrites. About $1 \mathrm{ml}$ sodium nitroprusside (5 $\mathrm{mM}$ ) in $0.5 \mathrm{M}$ phosphate buffer was mixed with $3 \mathrm{ml}$ of different concentrations $(20-100 \mu \mathrm{g} / \mathrm{ml})$ of the extracts and incubated at $25^{\circ} \mathrm{C}$ for $150 \mathrm{~min}$. It was then reacted with Greiss reagent (1 sulphanilamide in $2 \% \mathrm{H}_{3} \mathrm{PO}_{4}$ and $0.1 \% \mathrm{~N}-1$-napthylethylene diamine dihydrochloride in water). The absorbance of the chromophore formed during the diazotization of nitrite was read at $546 \mathrm{~nm}$. The same reaction mixture without the extracts but with equivalent amount of $0.5 \mathrm{M}$ phosphate buffer served as control. Ascorbic acid was used as a standard. The capability to scavenge the nitric oxide radical was calculated using the following equation: 
NO scavenged $(\%)=\left(\left(\mathrm{A}_{\mathrm{C}}-\mathrm{A}_{\mathrm{T}}\right) \times 100\right) /\left(\mathrm{A}_{\mathrm{C}}\right)$

where,

$A_{C}$ is the absorbance of the control.

$\mathrm{A}_{\mathrm{T}}$ is the absorbance of the extracts/standard

\subsection{Animals}

Male Wistar rats (200-250 g) were used for this study. Animals were housed in polypropylene cages under standard laboratory conditions and maintained at $25 \pm 2^{\circ} \mathrm{C}$, relative humidity $60 \pm 10 \%$ and 12:12 h light/dark cycle. The animals had free access to standard pellet diets and RO water ad libitum. The study protocol was approved by the Institutional Animal Ethical Committee (IAEC) of Committee for the Purpose of Control and Supervision of Experiments on Animals (648/02/C/CPCSEA).

\subsection{Ethylene glycol-induced urolithiasis}

Animals were divided into seven different groups having six animals in each group $(\mathrm{n}=6)$. Ethylene glycol $(\mathrm{EG}, 0.75 \% \mathrm{v} / \mathrm{v})$ in drinking water was fed to all groups except normal control (Group I) for induction of renal calculi till $28^{\text {th }}$ day (Afzal et al., 2021). Two types of studies were performed, viz., preventive and curative study. Groups IV and V were treated with alcoholic and aqueous extracts ( $250 \mathrm{mg} / \mathrm{kg}$ body weight), respectively, from day one to day $28^{\text {th }}$ and served as preventive regimen whereas Groups VI and VII were treated with alcoholic and aqueous extracts $(250 \mathrm{mg} / \mathrm{kg}$ body weight), respectively, from day 15 to day $28^{\text {th }}$ and served as curative regimen. Group III served as standard group and was treated with standard drug cystone $(750 \mathrm{mg} / \mathrm{kg}$ body weight $)$.

Group I : No treatment (normal control).

Group II : Ethylene glycol $(0.75 \%)$ in drinking water + vehicle (disease control).

Group III : Ethylene glycol $(0.75 \%)$ in drinking water + cystone (750 mg/kg) (standard).

Preventive regimen (day one-to-day $28^{\text {th }}$ ).

Group IV : Ethylene glycol $(0.75 \%)$ in drinking water + alcoholic extract $(250 \mathrm{mg} / \mathrm{kg})$.

Group V : Ethylene glycol $(0.75 \%)$ in drinking water + aqueous extract $(250 \mathrm{mg} / \mathrm{kg})$.

Curative regimen (day 15 to day $28^{\text {th }}$ ).

Group VI : Ethylene glycol $(0.75 \%)$ in drinking water + alcoholic extract $(250 \mathrm{mg} / \mathrm{kg})$.

Group VII : Ethylene glycol $(0.75 \%)$ in drinking water + aqueous extract $(250 \mathrm{mg} / \mathrm{kg})$.

All doses were prepared in distilled water using $10 \%$ tween 80 as suspending agent. The test substances were administered orally once daily through oral gavage tube.

\subsection{Evaluation of antiurolithiatic activity}

\subsubsection{Collection and analysis of urine}

Rats were kept separately in metabolic cages and urine samples of $24 \mathrm{~h}$ were collected on $28^{\text {th }}$ day of calculi induction treatment. Animals had free access to drinking water during the urine collection period. $\mathrm{pH}$ of urine was determined using narrow range $\mathrm{pH}$ paper and urine volumes were noted. A drop of concentrated hydrochloric acid was added to the urine sample before being stored at $4^{\circ} \mathrm{C}$. Urine was analyzed for calcium (Mustafa and Medeiros, 1985), phosphorus (Fiske and Subbarow, 1925). Magnesium, and uric acid contents in urine was analysed spectrophotometrically using commercially available biochemical kit and as per the manufacturer's instruction. Oxalate content was determined by precipitation method (Hodgkinson and Williams, 1972).

\subsubsection{Serum analysis}

Blood was collected from the retro-orbital plexus under anaesthesia at the end of the experiment, i.e., on $29^{\text {th }}$ day of experiment. Serum was separated by centrifugation at $10,000 \times \mathrm{g}$ for $10 \mathrm{~min}$ and was analyzed for creatinine, uric acid, and phosphorous content using commercially available biochemical kit.

\subsection{Statistical analysis}

Data were analyzed by Graph Pad PRISM 9. The data were expressed as mean \pm SEM. Statistical significance between means were analyzed by one-way analysis of variance (ANOVA), followed by "Dunnett's test". P value $<0.05$ was considered statistically significant.

\section{Results}

\subsection{Phytochemical screening of phytoconstituents}

C. chinensis root extracts were qualitatively analyzed for various phytoconstituents and it revealed the presence of carbohydrate, flavonoids, steroids, alkaloids, saponin, glycosides and phenolic compounds. The percentage yield was $4.29 \%$ and $5.22 \%$ for ethanol and water extract, respectively.

\subsection{DPPH free radical scavenging activity}

Figure 1 shows the DPPH free radical scavenging activity of the extracts and standard. Both the extracts showed nearly similar DPPH free radical scavenging activity. At a concentration of $80 \mu \mathrm{g} / \mathrm{ml}$, the scavenging activity of both the extracts was $59.33 \pm 0.44$, and $60.12 \pm 0.04 \%$, respectively, whereas at the same concentration, the standard was $52.81 \pm 0.69 \%$. The $\mathrm{IC}_{50}$ of ethanolic and aqueous extracts of $C$. chinensis roots was 57.25 and $59.97 \mu \mathrm{g} / \mathrm{ml}$, respectively and the $\mathrm{IC}_{50}$ of standard was $47.09 \mu \mathrm{g} / \mathrm{ml}$ (Figure 2). Ethanolic extract has a slightly better antioxidant potential compared to aqueous extract. The free radical scavenging activity was in the following order: $\mathrm{AA}>\mathrm{EE}>\mathrm{AE}$.

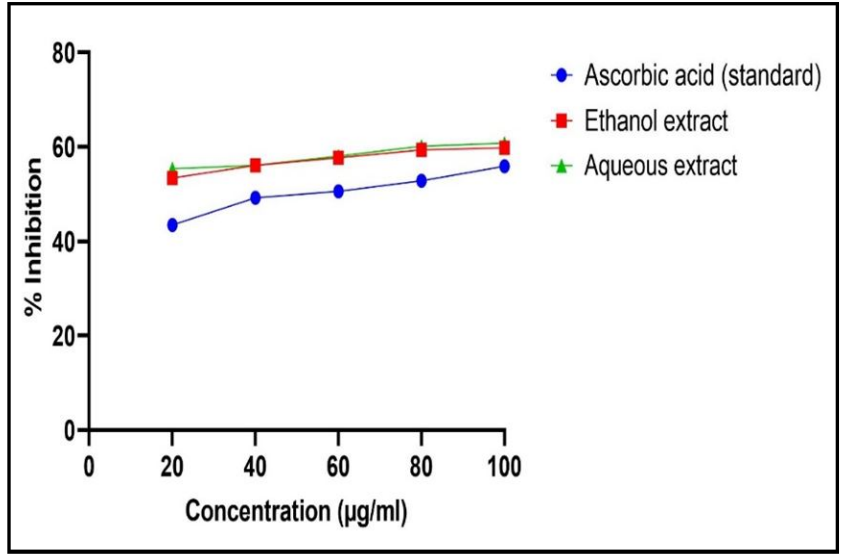

Figure 1: DPPH radical scavenging activity. 


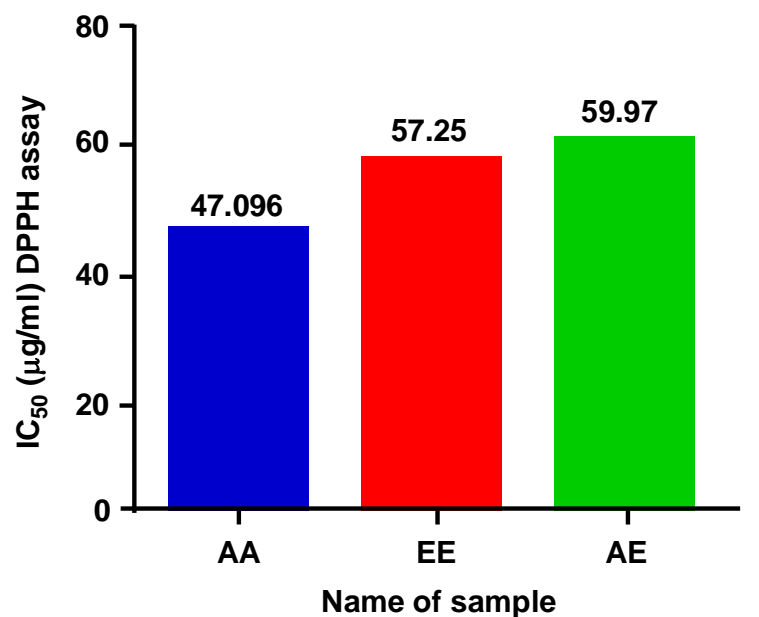

Figure 2: $\mathrm{IC}_{50}$ for DPPH scavenging activity (AA: ascorbic acid, EE:ethanolic extract, AE:aqueous extract). All experiments were performed in triplicate. Data are expressed as mean \pm SEM.

\subsection{Ferrous reducing antioxidant capacity (FRAC)}

The ethanolic and aqueous extracts of $C$. chinensis roots showed high FRAC with an increase in the concentration of the extracts. At $100 \mu \mathrm{g} / \mathrm{ml}$, the absorbance of ethanolic and aqueous extracts of C. chinensis roots was $4.146 \pm 0.037$ and $3.916 \pm 0.054$, respectively. A higher absorbance indicates a higher reducing power. These results established that the both the extracts of $C$. chinensis roots possessed the FRAC (Figure 3).

\subsection{Nitric oxide scavenging activity}

Figure 4 depicts the nitric oxide scavenging activity of both the extracts of $C$. chinensis roots. Both the extracts showed a moderate nitric oxide radicals scavenging activity.

\subsection{Effect on urine volume and urinary $\mathrm{pH}$}

The values reported in Table 1 shows the urinary volume and $\mathrm{pH}$. Regarding urinary volume, there was a significant decrease in urinary output in disease group (Group II), while extract $(250 \mathrm{mg} / \mathrm{kg}$ ) and cystone $(750 \mathrm{mg} / \mathrm{kg})$ treated group showed significant increase in urinary output as compared to disease control group on $28^{\text {th }}$ day. Moreover, a significant decrease in urinary $\mathrm{pH}$ was observed in the untreated disease group, which was significantly increased in extract treated $(250 \mathrm{mg} / \mathrm{kg})$ and standard $(750 \mathrm{mg} / \mathrm{kg})$ group.

Table 1: Effect of $C$. chinensis root extracts on urinary parameters in ethylene glycol induced urolithiasis in rats on $28^{\text {th }}$ day

\begin{tabular}{|c|c|c|c|c|c|c|c|}
\hline \multirow[b]{2}{*}{ Parameter } & \multirow[b]{2}{*}{$\begin{array}{l}\text { Group I } \\
\text { (Normal } \\
\text { control) }\end{array}$} & \multirow[b]{2}{*}{$\begin{array}{l}\text { Group II } \\
\text { (Disease } \\
\text { control) }\end{array}$} & \multirow[b]{2}{*}{$\begin{array}{l}\text { Group III } \\
\text { (Cystone } \\
\text { @750 mg/kg) }\end{array}$} & \multicolumn{2}{|c|}{ Preventive regimen } & \multicolumn{2}{|c|}{ Curative regimen } \\
\hline & & & & $\begin{array}{l}\text { Group IV } \\
\text { (Ethanolic } \\
\text { extract@ } \\
250 \text { mg/kg) }\end{array}$ & $\begin{array}{l}\text { Group V } \\
\text { (Aqueous } \\
\text { extract } \\
\text { @ } 250 \mathrm{mg} / \mathrm{kg} \text { ) }\end{array}$ & $\begin{array}{l}\text { Group VI } \\
\text { (Ethanolic } \\
\text { extract } \\
\text { @ } 250 \mathrm{mg} / \mathrm{kg} \text { ) }\end{array}$ & $\begin{array}{l}\text { Group VII } \\
\text { (Aqueous } \\
\text { extract } \\
\text { @ } 250 \mathrm{mg} / \mathrm{kg} \text { ) }\end{array}$ \\
\hline $\begin{array}{l}\text { Urine volume } \\
(\mathrm{ml} / 24 \mathrm{~h})\end{array}$ & $11.98 \pm 0.29$ & $5.06 \pm 0.35$ & $11.51 \pm 1.03^{* * *}$ & $13.8 \pm 0.10 * * *$ & $12.1 \pm 0.63 * * *$ & $9.6 \pm 0.32 * * *$ & $8.3 \pm 0.02 * *$ \\
\hline Urinary $\mathrm{pH}$ & $7.35 \pm 0.21$ & $5.58 \pm 0.58$ & $7.36 \pm 0.81^{*}$ & $7.25 \pm 0.34$ & $7.3 \pm 0.26^{*}$ & $7.3 \pm 0.12 *$ & $7.21 \pm 0.08$ \\
\hline $\begin{array}{l}\text { Oxalate } \\
(\mathrm{mg} / 24 \mathrm{~h})\end{array}$ & $0.32 \pm 0.02$ & $2.56 \pm 0.16$ & $0.41 \pm 0.01 * * *$ & $0.57 \pm 0.05 * * *$ & $0.84 \pm 0.05^{* * *}$ & $0.72 \pm 0.03 * * *$ & $1.06 \pm 0.05 * * *$ \\
\hline $\begin{array}{l}\text { Calcium } \\
(\mathrm{mg} / 24 \mathrm{~h})\end{array}$ & $4.73 \pm 0.43$ & $7.04 \pm 0.29$ & $4.44 \pm 0.36 * * *$ & $4.47 \pm 0.43 * * *$ & $5.04 \pm 0.29 * * *$ & $5.8 \pm 0.057 * * *$ & $5.41 \pm 0.038^{* * *}$ \\
\hline $\begin{array}{l}\text { Uric acid } \\
(\mathrm{mg} / 24 \mathrm{~h})\end{array}$ & $4.60 \pm 0.11$ & $7.84 \pm 0.14$ & $4.71 \pm 0.21 * * *$ & $4.0 \pm 0.10 * * *$ & $5.01 \pm 0.07 * * *$ & $4.9 \pm 0.18 * * *$ & $5.14 \pm 0.11 * * *$ \\
\hline $\begin{array}{l}\text { Magnesium } \\
(\mathrm{mg} / 24 \mathrm{~h})\end{array}$ & $2.46 \pm 0.10$ & $0.59 \pm 0.02$ & $2.32 \pm 0.09 * * *$ & $2.38 \pm 0.04 * * *$ & $1.95 \pm 0.03 * * *$ & $2.05 \pm 0.05 * * *$ & $1.37 \pm 0.04 * * *$ \\
\hline $\begin{array}{l}\text { Phosphate } \\
(\mathrm{mg} / 24 \mathrm{~h})\end{array}$ & $3.64 \pm 0.38$ & $6.89 \pm 0.16$ & $3.48 \pm 0.16^{* * *}$ & $3.6 \pm 0.10 * * *$ & $4.03 \pm 0.05 * * *$ & $4.12 \pm 0.04 * * *$ & $4.8 \pm 0.05 * * *$ \\
\hline
\end{tabular}

All values are mean \pm SEM $(\mathrm{n}=6)$, one-way ANOVA followed by Dunnett's test. Group II was used to compare with all other groups. *** $p<0.001, * * p<0.01, * p<0.05$

\subsection{Effect on urinary parameters}

Ethylene glycol feeding resulted in hyperoxaluria, hypercalciuria as well as increased renal excretion of phosphate. The values for urinary analysis reported in Table 1 , showed that oxalate was significantly higher in untreated nephrolithiasic rats. However, it has significantly reduced in rats treated with $C$. chinensis root extracts. Urinary calcium and phosphorous level also decreased significantly in treated rats compared to untreated nephrolithiasicrats. For magnesium, there was a significant reduction in its value that increased to the normal following treatment. Similarly, there was a significant reduction in urinary uric acid level in all the treated groups. Treatment with $C$. chinensis root extracts and cystone significantly reduced the levels of calcium, phosphorus, oxalate, creatinine and uric acid along with increased the magnesium level when compared to the disease control group.

\subsection{Effect on serum parameters}

In Group II, marked renal damage was seen by the elevated serum levels of creatinine, uric acid and phosphorous. However, 
prophylactic and therapeutic treatment with $C$. chinensis root extracts significantly restored the elevated serum levels of creatinine and uric acid (Table 2).

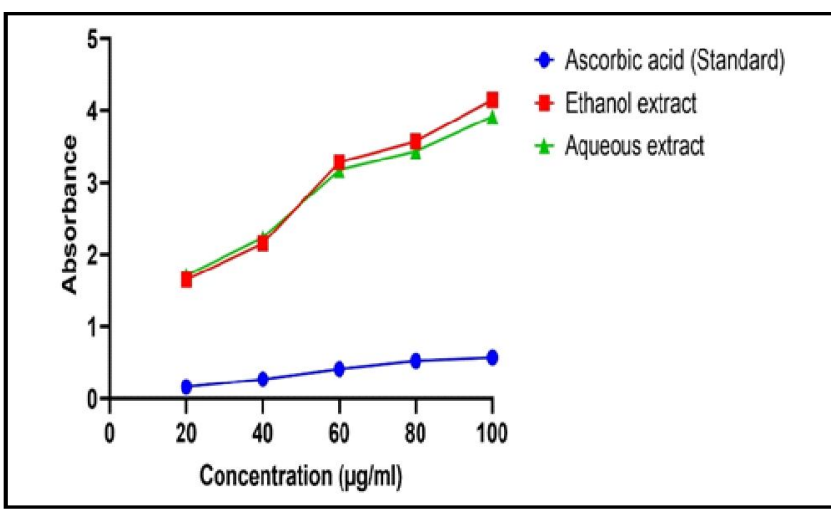

Figure 3: Ferrous reducing antioxidant capacity (FRAC).

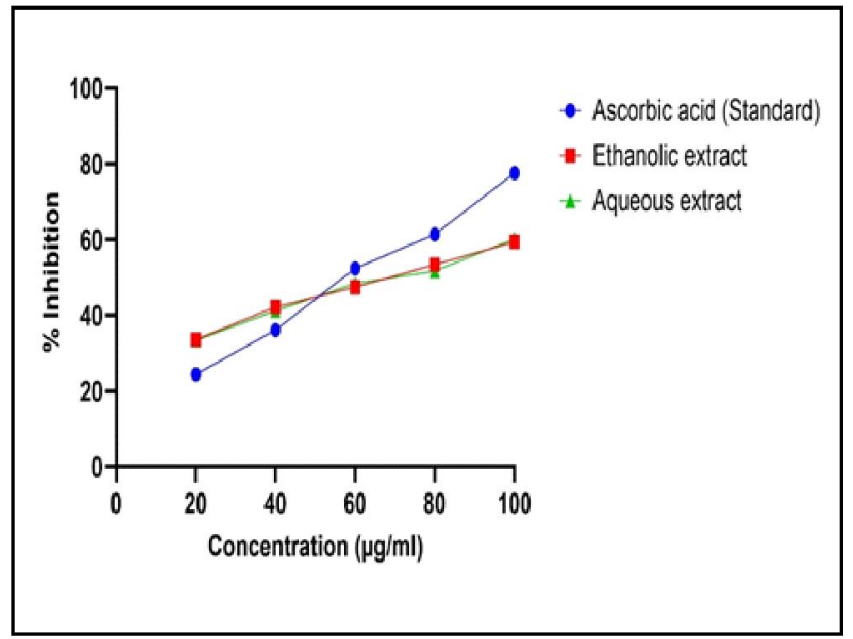

Figure 4: Nitric oxide scavenging activity.

Table 2: Effect of $C$. chinensis root extracts on serum parameters in ethylene glycol induced urolithiasis in rats

\begin{tabular}{|c|c|c|c|c|c|c|c|}
\hline \multirow[b]{2}{*}{ Parameter } & \multirow[b]{2}{*}{$\begin{array}{l}\text { Group I } \\
\text { (Normal } \\
\text { control) }\end{array}$} & \multirow[b]{2}{*}{$\begin{array}{l}\text { Group II } \\
\text { (Disease } \\
\text { control) }\end{array}$} & \multirow[b]{2}{*}{$\begin{array}{l}\text { Group III } \\
\text { (Cystone } \\
@ 750 \mathrm{mg} / \mathrm{kg} \text { ) }\end{array}$} & \multicolumn{2}{|c|}{ Preventive regimen } & \multicolumn{2}{|c|}{ Curative regimen } \\
\hline & & & & $\begin{array}{l}\text { Group IV } \\
\text { (Ethanolic } \\
\text { extract@ } \\
250 \mathrm{mg} / \mathrm{kg} \text { ) }\end{array}$ & $\begin{array}{l}\text { Group V } \\
\text { (Aqueous } \\
\text { extract } \\
\text { @ } 250 \mathrm{mg} / \mathrm{kg} \text { ) }\end{array}$ & $\begin{array}{l}\text { Group VI } \\
\text { (Ethanolic } \\
\text { extract } \\
\text { @ } 250 \mathrm{mg} / \mathrm{kg} \text { ) }\end{array}$ & $\begin{array}{l}\text { Group VII } \\
\text { (Aqueous } \\
\text { extract } \\
@ 250 \mathrm{mg} / \mathrm{kg} \text { ) }\end{array}$ \\
\hline $\begin{array}{l}\text { Creatinine } \\
(\mathrm{mg} / \mathrm{dl})\end{array}$ & $0.51 \pm 0.10$ & $1.51 \pm 0.13$ & $0.51 \pm 0.04 * * *$ & $0.55 \pm 0.09 * * *$ & $0.9 \pm 0.09 * * *$ & $0.81 \pm 0.07 * * *$ & $1.2 \pm 0.08$ \\
\hline $\begin{array}{l}\text { Uric acid } \\
(\mathrm{mg} / \mathrm{dl})\end{array}$ & $2.55 \pm 0.12$ & $5.13 \pm 0.09$ & $2.89 \pm 0.21 * * *$ & $2.91 \pm 0.07 * * *$ & $3.24 \pm 0.07 * * *$ & $3.10 \pm 0.03 * * *$ & $3.81 \pm 0.14^{* *}$ \\
\hline $\begin{array}{l}\text { Phosphate } \\
(\mathrm{mg} / \mathrm{dl})\end{array}$ & $3.15 \pm 0.17$ & $5.96 \pm 0.17$ & $3.14 \pm 0.06 * * *$ & $3.25 \pm 0.04 * * *$ & $4.85 \pm 0.04 * * *$ & $4.4 \pm 0.05 * * *$ & $5.2 \pm 0.05 * * *$ \\
\hline
\end{tabular}

All values are mean \pm SEM $(n=6)$, one-way ANOVA followed by Dunnett's test. Group II was used to compare with all other groups. *** $p<0.001, * * p<0.01$.

\section{Discussion}

Plants are a rich source of large number of bioactive compounds with high antioxidant activity. Determination of the antioxidant activity of different plant species and its parts could contribute to the identification of these plants as a source of new antioxidant compounds. Different in vitro methods are being used to quantify antioxidant activities of plant extracts that includes, 2,2-di-phenyl1-picrylhydrazyl (DPPH) radical scavenging assay, reducing power assay and nitric oxide scavenging assay. Oxidative stress is one of the major risk factor in the pathogenesis of numerous diseases. Free radicals and reactive oxygen species (ROS) plays an important role in the pathogenesis of various diseases that may lead to the conditions like such as diabetes, hypertension, Parkinson's disease, cancers and chronic kidney disease (CKD) including urinary stones.

DPPH free radical method is an antioxidant assay based on electrontransfer that produces a violet solution in ethanol. This free radical, stable at room temperature, is reduced in the presence of an antioxidant molecule, giving rise to colorless ethanol solution. DPPH assay is an easy and rapid way to evaluate antioxidants by spectrophotometry. The effect of antioxidants on DPPH is supposed to be due to their hydrogen donating ability. Free radical scavenging activities are very important to prevent the damaging effect of free radicals in different diseases, including urinary stone.
DPPH free radical scavenging is a commonly used method for screening the antioxidant activity of plant extracts. Our results revealed that extracts of $C$. chinensis roots had a nearly similar free radical scavenging activity when compared with standard ascorbic acid.

Reducing power is broadly used in the evaluation of antioxidant activity of plant extracts. The reducing power is generally related with the presence of reductants, which exert antioxidant action by breaking the free radical chains by donating a hydrogen atom (Rahman et al., 2015). The iron reducing capacity of the ethanolic and aqueous extracts of $C$. chinensis roots was estimated from their capacity to reduce the $\mathrm{Fe}^{3+}$-ferricyanide complex to the ferrous form by donating an electron. All the extracts showed a good concentration-dependent reducing power capacity. The reducing power increase with an increase in extract concentrations.

Nitric oxide (NO) known as endothelium-derived relaxing factor is produced by different types of cells, including macrophages, neurons, platelets and involved in many physiological and pathological processes (Hou et al., 1999). Nitrite ions after reacting with Griess reagent, forms a purple azo dye. In presence of an antioxidants, the amount of nitrites decreases and this decrease in the formation of purple azo dye reflect the extent of scavenging of test compounds (Senguttuvan et al., 2014). The extracts possibly 
inhibited the accumulation of nitrite formed during the reaction of nitric oxide with oxygen. Both the extracts of $C$. chinensis roots are found to be a good scavenger of nitric oxide radicals. In a similar study with the leaf extracts of $C$. chinensis, a significant antioxidant potential was observed when compared with the standard ascorbic acid (Boxi et al., 2010). The antioxidant activity is generally attributed to phenolic compounds in plant extracts. We assume that the antioxidant potential and reducing power capacity of the extracts was probably due to the presence of polyphenols, which can act as free radical scavenger by donating an electron or hydrogen. In the present study, the root extracts of $C$. chinensis roots presented an excellent free radical scavenging efficacy. It suggests that the extract is a potential therapeutic agent for the control of oxidative damage caused by the various free radicals.

Oxidative stress clearly plays an active role in urolithiasis and in human studies it has been shown that stone formers have increased oxidative stress and renal tubular injury relative to the non-stone formers (Boonla, 2018). ROS plays an important role in the formation of $\mathrm{CaOx}$ kidney stones by regulating crystal formation, growth and retention and antioxidant treatments reduce crystal and oxalate induced injury (Khan, 2014). A diet rich in antioxidants has been shown to reduce stone episodes (Taylor et al., 2009). We assume that the roots of $C$. chinensis could be a vital source of antioxidants while combating urinary stone disease. The free radical scavenging property of $C$. chinensis roots may help in reducing the oxidative stress observed during the formation of urinary stone.

Several animal models have been used to study hyperoxaluria, its consequences and the mechanisms involved in the formation of urinary stones, Ethylene glycol (EG) induced hyperoxaluria is the simplest and the most popular model. EG is readily absorbed along the intestine and is metabolized in the liver to oxalate without producing metabolic acidosis in rats (Green et al., 2005). However, the use of EG in experimental models has been criticized as it produces metabolic acidosis in humans (Evan et al., 2004). Rat has been found to be a suitable species for study of calcium oxalate deposition in the kidneys, a process that mimics the etiology of kidney stone formation in humans (Atmani et al., 2004). Male rats were selected to induce urolithiasis because the incidence of stone formation is more common in male than in female. The pathophysiological mechanisms for calcium kidney stone formation (calculogenesis) are complex and diverse and include low urine volume, hypercalciuria, hyperuricosuria, hyperoxaluria, and abnormalities in urine pH (Sakhaee et al., 2012), as seen here in EG treated rats.

We observed that urinary volume increased in rats receiving EG and the root extracts compared to those receiving EG only. The results indicated that diuretic potential of the extract, which will help in the rapid dissolution of the preformed stones and prevention of new stone formation. Treatment with root extracts increased urine volume ultimately decreasing the saturation of oxalate and calcium ions and prevented the calcium oxalate crystal formation. Several studies showed that administration of EG in animals caused decreased urine output and this decrease in urine volume increases the saturation level of oxalate, and thus initiating the calcium oxalate crystal formation (Patel and Acharya, 2020).

Urinary $\mathrm{pH}$ is a major factor for kidney stone formation. In the present study, urinary $\mathrm{pH}$ of disease group was significantly decreased. EG-treated rats without extract treatment has acidic urine. Acidic urine $\mathrm{pH}$ may promote calcium oxalate $(\mathrm{CaOx})$ stone formation, whereas the basic urine $\mathrm{pH}$ may help to prevent $\mathrm{CaOx}$ kidney stone disease (Manissorn et al., 2017). pH of urine in test extracts treated rats were found significantly increased, which indicates that treatment with root extract may have increased the solubility of calcium oxalate stone and decreased the supersaturation. However, in another study, it was reported that a low urine $\mathrm{pH}$ is the most important factor leading to uric acid stone formation, whereas the benefit of increasing urine $\mathrm{pH}$ in calcium oxalate stone formers with low urine $\mathrm{pH}$ is uncertain (Carvalho and Carvalho, 2018).

Hyperoxaluria is a more significant risk factor in the pathogenesis of renal stone (Tiselius, 1997). In the present study, EG-treated rats exhibited significant hyperoxaluria and an increased renal clearance of oxalate. The reduction in oxalate excretion was observed on treatment with $C$. chinensis extracts. This decreased excretion of oxalate may be due to the inhibition of formation of oxalate by the root extract.

High urine calcium is the single most common abnormality of urine chemistry in recurrent stone formers and increased urinary calcium excretion, may be due to increased gastrointestional absorption, increased bone resorption or increased tubular reabsorption (Dawson and Tomson, 2012). EG caused an increase in calcium urinary excretion (hypercalciuria) in the untreated group. Supplementation with $C$. chinensis root extracts and cystone, restored oxalate and calcium in urine in both curative as well as preventive regimens as compared to untreated animals. Increased urinary levels of calcium and oxalate helps in the nucleation and precipitated calcium oxalate attached to renal tubules and creates more nucleation centers for new calcium oxalate crystals (Patel and Acharya, 2020).

EG caused a marked increase in urinary uric acid excretion (hyperuricosuria).This hyperuricosuria may be attributed to the physicochemical process to urinary supersaturation with colloidal monosodium urate-induced calcium oxalate crystallization (Pak and Arnold, 1975). This increase in uric acid excretion was significantly reduced following $C$. chinensis extract treatment.

Magnesium is a known inhibitor of the formation of calcium oxalate crystals in the urine (Johansson et al., 1982). Magnesium can inhibit calcium oxalate crystal formations in urine, binding free oxalate and increasing its solubility (Siener and Hesse, 1995). Urinary magnesium was significantly reduced in ethylene glycol induced urolithic rats (Group II). Treatment with extracts restored the magnesium level, and thereby diminishes the growth of calcium oxalate crystals in rats treated with extracts. It has been reported that the dietary interventions with magnesium may results in the decrease of urinary supersaturation for lithogenic salts (Ferraro et al., 2020).

Increased urinary phosphate as well as oxalate provide an ideal condition for stone formation by forming calcium phosphate crystals (Divakar et al., 2010). There was a significant increase in excretion of inorganic phosphate level in urine. Treatment with $C$. chinensis extract significantly lowered the elevated levels of phosphate in both the regimens, subsequently reducing the chances of calculi formation.

There are significant differences in glomerular filtration rate (GFR) between stone formers and non-stone formers. In urolithiasis, the 
glomerular filtration rate (GFR) decreases due to the obstruction to the flow of urine by stones in urinary system. Due to this, the waste products, particularly nitrogenous substances such as urea, creatinine and uric acid get accumulated in blood. The most commonly used endogenous marker for the assessment of glomerular function is creatinine (Gounden et al., 2020). Marked renal damage was seen in EG treated rats as indicated by the elevated serum levels of creatinine and uric acid which are markers of glomerular and tubular damage. Treatment with $C$. chinensis extract in treated rats showed to prevent the elevation of serum levels of these markers both in preventive and curative regimen.

\section{Conclusion}

This study established that the administration of root extract of $C$. chinensis reduced and prevented the formation and growth of urinary stones in both preventive as well as curative dose regimen; however, it was more pronounced in preventive regimen. Both alcoholic as well as aqueous extract shown their antiurolithiatic activity but alcoholic extract was found to be more efficacious that the aqueous extract. This anti-urolithiatic effect may be attributed to the presence of alkaloids, polyphenols and flavonoids which wields its antioxidant potential, or promotion of inhibitors like magnesium and reduction in the urinary concentration of urinary stone-forming constituents.

\section{Acknowledgements}

The authors are grateful to the Principal, Jhau Lal Chaturvedi College of Pharmacy, Nagpur, Maharashtra, India for providing necessary facilities.

\section{Conflict of interest}

The authors declare no conflicts of interest relevant to this article.

\section{References}

Aggarwal, K.P.; Narula, S.; Kakkar, M. and Tandon, C. (2013). Nephrolithiasis: molecular mechanism of renal stone formation and the critical role played by modulators. Bio. Med. Res. Int., 13:1-21.

Atmani, F.; Slimani, Y.; Mimouni, M.; Aziz, M.; Hacht, B and Ziyyat, A. (2004). Effect of aqueous extract from Hernia riahirsuta L. on experimentally nephrolithiasic rats. J. Ethnopharmacol., 95(1):87-93.

Bhat, A.; Singh, V.; Bhat, M.; Kumar, V and Bhat, A. (2018). Spectrum of urinary stone composition in Northwestern Rajasthan using fourier transform infrared spectroscopy. Indian J. Urol., 34(2):144-148.

Blois, Marsden S. (1958). Antioxidant determinations by the use of a stable free radical. Nature, 181(4617):1199-1200.

Boonla, Chanchai (2018). Oxidative stress in urolithiasis. reactive oxygen species (ROS) in living cells, Cristiana Filip and Elena Albu, Intech. Open, London, UK, pp:1-21.

Boxi, M.; Rajesh, Y.; Kumar, V.R.; Praveen, B. and Mangamma, K. (2010). Extraction, phytochemical screening and in vitro evaluation of antioxidant properties of Commicarpus chinesis (aqueous leaf extract). Int. J. Pharma. Bio. Sci., 1(4):537-547.

Carvalho, M. and Carvalho, M. (2018). Urinary $\mathrm{pH}$ in calcium oxalate stone formers: Does it matter? J. Bras. Nefrol., 40(1):6-7.

Dawson, C.H. and Tomson, C.R. (2012). Kidney stone disease: Pathophysiology, investigation and medical treatment. Clin. Med., 12(5):467471
Divakar, K.; Pawar, A.T.; Chandrasekhar, S.B.; Dighe, S.B and Divakar, G. (2010). Protective effect of the hydro-alcoholic extract of Rubia cordifolia roots against ethylene glycol induced urolithiasis in rats. Food Chem. Toxicol., 48(4):1013-1018.

Evan,A.P.; Bledsoe, S.B.; Smith, S.B and Bushinsky, D.A. (2004). Calcium oxalate crystal localization and osteopontin immunostaining in genetic hypercalciuric stone-forming rats. Kidney Int., 65(1):154-161.

Ferraro, P.M.; Bargagli, M.; Trinchieri, A and Gambaro, G. (2020). Risk of kidney stones: Influence of dietary factors, dietary patterns, and vegetarianvegan diets. Nutrients, 12(3):1-16.

Fiske, C.H. and Subbarow, Y. (1925). The colorimetric determination of phosphorus. J. Biol. Chem., 66(2):375-400.

Goncalves, S.; Moreira, E.; Grosso, C.; Andrade, P.B.;Valentao, P and Romano, A. (2017). Phenolic profile, antioxidant activity and enzyme inhibitory activities of extracts from aromatic plants used in Mediterranean diet. J. Food Sci. Technol., 54(1):219-227.

Gounden, V.; Bhatt, H and Jialal, I. (2020). Renal Function Tests. Stat Pearls Publishing, Treasure Island (FL).

Green, M.L; Hatch, M. and Freel, R.W. (2005). Ethylene glycol induces hyperoxaluria without metabolic acidosis in rats. Am. J. PhysiolRen. Physiol., 289(3):F536-F543.

Guha, M.; Banerjee, H.; Mitra, P. and Das, M. (2019). The demographic diversity of food intake and prevalence of kidney stone diseases in the Indian continent. Foods, 8(37):1-17.

Halkai, M.A.;Mahurkar, N.; Ahmed M.D.A.; Beknal, A.K.; Hasan, S.M.; Sayeed Ul Hasan, S.M. and Swathi, M. (2012). Evaluation of gastroprotective effect of aqueous leaf extract of Commicarpus chinensis in pylorus ligted albino rats. Res. J. Pharmacol. Pharmacodyn., 4(5):307-310.

Hodgkinson, A. and Williams, A. (1972). An improved colorimetric procedure for urine oxalate. Clinica. Chimica. Acta., 36(1):127-132.

Hou, Y.C.; Janczuk, A. and Wang, P.G. (1999). Current trends in the development of nitric oxide donors. Curr. Pharm. Des., 6:417-441.

Huyut, Z.; Beydemir, S. and Gulcin, I. (2017). Antioxidant and antiradical properties of selected flavonoids and phenolic compounds. Biochem. Res. Int., 10:e7616791.

Johansson, G.; Backman, U.; Danielson, B.G.; Fellstrom, B.; Ljunghall, S and Wikstrom, B. (1982). Effects of magnesium hydroxide in renal stone disease. J. Am. Coll. Nutr., 1(2):179-185.

Karadi, R.V.; Gadge, N.B.; Alagawadi, K.R and Savadi, R.V. (2006). Effect of Moringa oleifera Lam. root-wood on ethylene glycol induced urolithiasis in rats. J. Ethnopharmacol., 105(1-2):306-311.

Khan, Saeed R (2014). Reactive oxygen species, inflammation and calcium oxalate nephrolithiasis. Transl. Androl. Urol., 3(3):256-276.

Kirkali, Z.; Rasooly, R.; Star, R.A and Rodgers, G.P. (2015). Urinary stone disease: progress, status, and needs. Urology, 86(4):651-653.

Laikangbam, R. and Damayanti Devi, M. (2012). Inhibition of calcium oxalate crystal deposition on kidneys of urolithiatic rats by Hibiscus sabdariffa L. extract. Urol. Res., 40(3):211-218.

Li, X.; Liang, Q.; Sun, Y.; Diao, L.; Qin, Z.; Wang, W.; Lu, J.; Fu, S.; Ma, B and Yue, Z. (2015). Potential mechanisms responsible for the antinephrolithic effects of an aqueous extract of Fructus aurantii. Evid. Based Complement. Alternat. Med., 15:1-11.

Lobo, V.; Patil, A.; Phatak, A. and Chandra, N. (2010). Free radicals, antioxidants and functional foods: Impact on human health. Pharmacogn. Rev., 4(8):118-126.

Madhurkar, N. and Sayeed, U.l. Hasan, S.M. (2014). Antiulcer antiulcer activity of Commicarpus chinensis in ethanol and aspirin induced ulcers. Asian J. Pharmaceutical Res., 4(3):119-122. 
Madhurkar, N.; Sayeed UI Hasan, S.M. and Quadri Syed, M. (2014). Antiinflammatory and analgesic influence of aqueous leaf extract of Commicarpus chinensis. Asian J. Pharmacy Tech., 4(2):59-62.

Manissorn, J.; Fong-ngern, K.; Peerapen, P. and Thongboonkerd, V. (2017) Systematic evaluation for effects of urine $\mathrm{pH}$ on calcium oxalate crystallization, crystal-cell adhesion and internalization into renal tubular cells. Sci. Rep., 7(1):17-98.

Marcocci, L.; Maguire, J.J.; Droy Lefaix, M.T and Packer, L. (1994). The nitric oxide-scavenging properties of Ginkgo biloba extract EGb 761 Biochem. Biophys. Res. Commun., 201(2):748-755.

McAteer, J.A. and Evan, A.P. (2008). The acute and long-term adverse effects of shock wave lithotripsy. Semin Nephrol., 28(2):200-213.

Mosquera, D.M.G.; Ortega, Y.H.; Quero, P.C.; Martínez, R.S and Pieters, L. (2020). Antiurolithiatic activity of Boldoa purpurascens aqueous extract: An in vitro and in vivo study. J. Ethnopharmacol., 253:112691.

Mustafa, F.A. and Medeiros, D.M. (1985). Proximate composition, mineral content, and fatty acids of catfish (Ictalurus punctatus, rafinesque) for different seasons and cooking methods. J. Food Sci., 50(3): 585-588.

Oyaizu, Makoto (1986). Studies on products of browning reaction. Antioxidative activities of products of browning reaction prepared from glucosamine. Jpn. J. Nutr. Diet, 44(6):307-315.

Pak, C.Y.C. and Arnold, L.H. (1975). Heterogeneous nucleation of calcium oxalate by seeds of monosodium urate. Exp. Biol. Med., 149(4): 930-932.

Patel, V.B. and Acharya, N. (2020). Effect of Macrotyloma uniflorum in ethylene glycol induced urolithiasis in rats. Heliyon, 6(6):e04253.

Purohit, A.P.; Kokate, C.K and Gokhale, S.B. (2020). A Text Book of Pharmacognosy (41st ed.). Nirali Prakashan, Pune, India, pp:238.
Rahman, Md. M.; Islam, Md. B.; Biswas, M and Khurshid Alam, A.H.M. (2015). In vitro antioxidant and free radical scavenging activity of different parts of Tabebuia pallida growing in Bangladesh. BMC Res. Notes, 8(1):621.

Sakhaee, K.; Maalouf, N.M and Sinnott, B. (2012). Kidney stones 2012: Pathogenesis, diagnosis, and management. J. Clin. Endocrinol. Metab., 97(6): 1847-1860.

Senguttuvan, J.; Paulsamy, S and Karthika, K. (2014). Phytochemical analysis and evaluation of leaf and root parts of the medicinal herb, Hypochaeris radicata $\mathrm{L}$. for in vitro antioxidant activities. Asian Pac. J. Trop. Biomed., 4(1):S359-S367.

Siener, R. and Hesse, A. (1995). Influence of a mixed and a vegetarian diet on urinary magnesium excretion and concentration. Br. J. Nutr., 73(5): 783-790.

Sofia, N.H.; Manickavasakam, K. and Walter, T.M. (2016). Prevalence and risk factors of kidney stone. Global Journal for Research Analysis, 5(3): 183-187.

Taylor, E.N.; Fung, T.T and Curhan, G.C. (2009). DASH-style diet associates with reduced risk for kidney stones. J. Am. Soc. Nephrol., 20(10): 2253-2259.

Tiselius, Hans-Goran (1997). Risk formulas in calcium oxalate urolithiasis. World J. Urol., 15(3):176-185.

Young, I.S. and Woodside, J.V. (2001). Antioxidants in health and disease. J. Clin. Pathol., 54(3):176-186.

Ziemba, J.B. and Matlaga, B.R. (2017). Epidemiology and economics of nephrolithiasis. Investig. Clin. Urol., 58(5):299-306. 